$\begin{array}{lrrrr}\begin{array}{l}\text { FOUNDATIONS } \\ \text { Vol. } 37\end{array} & \text { OF COMPUTING } & \text { AND } & \text { DECISION } & \text { SCIENCES } \\ & & \text { No12) } & \text { No. } 2\end{array}$

DOI: $10.2478 / \mathrm{v} 10209-011-0006-9$

\title{
Conflicts in Legal Knowledge Base
}

\author{
Tomasz ZUREK *
}

\begin{abstract}
The simulation of inference processes performed by lawyers can be seen as one way to create advisory legal system. In order to simulate such a process as accurately as possible, it is indispensable to make a clear-cut distinction between the provision itself, and its interpretation and inference mechanisms. This distinction would allow for preserving both the universal character of the provision and its applicability to various legal problems. The authors main objective was to model a selected legal act, together with the inference rules applied, and to represent them in an advisory system, focusing on the most accurate representation of both the content and inference rules. Given that the laws which stand in contradiction prove to be the major challenge, they will constitute the primary focus of this study.
\end{abstract}

Keywords: Legal expert system, Knowledge representation, Conflicting rules.

\section{Introduction}

A common practical use of advisory IT tools supporting legal opinions is still a far cry from the use of such tools in other fields. Major problems with implementing such tools stem from the nature of knowledge and legal interpretation, which show the features so disliked by computers and computer scientists, including under specification, imprecision, generality and a great deal of common-sense knowledge. Despite all these features, or perhaps owing to them, this proves to constitute a truly fascinating research area, whose practical potential can hardly be overestimated, not only with respect to legal expert systems. The research on legal opinion-supporting tools has been conducted on various planes, with modelling of legal acts in order to establish advisory tools being only one of the many research directions. The focus of this study is on the challenges of representing a statutory legal act in the knowledge base, and in particular on the issue of questionability of specific provisions. The analysis has

\footnotetext{
${ }^{*}$ Intitute of Computer Science Maria Curie-Sklodowska University, pl. Marii Curie-Sklodowskiej 1. Lublin
} 
been conducted on the basis of Article 3 of the Polish Agricultural Tax Act [1] which specifies who is and who is not an agricultural tax payer. Any further considerations are based on the authors view that legal provisions should be represented in the knowledge base as closely as possible to what has been stipulated in the wording of a given legal act, while both the general legal knowledge (the metaknowlege of the inference and interpretation) and common-sense knowledge should be separated from the direct wording of legal provisions. All these types of knowledge should be then integrated within the interpreting mechanism. This approach is close to the one suggested in [14], with a slightly different division of knowledge.

At this point, it may prove useful to focus on the legal act to be analysed. The Agricultural Tax Act constitutes an example of a statutory tax law, and as such should it be subject to grammatical (linguistic) interpretation. This means that no intent or objectives assumed by the legislator should be analysed, buy merely the strict letter of the law. Furthermore, the theory of law requires that any tax provisions be as precise and deterministic as possible, given that the majority of interpreting mechanisms, applied in other areas of the law, may not be used here. Therefore, lawyers issuing their opinions based on the reference law have a very limited leeway (however, this does not mean that grammatical interpretation is entirely unambiguous), their interpretation being much more grounded in the letter of the law than in the ability to construct the appropriate line of argumentation. In this event, representing legal provisions and the corresponding interpreting mechanisms might seem relatively easy. However, even such a straight-forward example poses an array of difficulties related to the modelling of the legal act, and to the corresponding interpreting mechanisms.

Construction of a model fragment of a real legal act, and its implementation in the legal advisory computer system, is the principal objective of this study. The model comprises the rules of law, including any related limitations. The study makes use of the conflicting rules model, derived from [7], and of the conflict solving model using the lex specialis principle, based on [18], [19]. The final part of the study deals with practical implementation of the model, which forms part of a larger system supporting legal opinions, described, inter alia, in [30].

\section{Related works}

This article discusses the issue of conflicting rules within the statutory fiscal law. The research made use of the results obtained in various studies focusing on the conflict issues in legal argumentation [2], especially in the studies dealing with the application of lex specialis derogat legi generali and defeasible logic [6], [8], [19], [17], [25], [24], [23] [28], as well as related to the rule-based representation of legal standards. [3], $[4],[27],[26]$. An array of studies on the argumentation process modelling is focused on the fight between two conflicting parties, and on the attacks at one anothers arguments. As regards the statutory tax law, the line of argumentation is usually less complex than in the systems described, inter alia, in [21], or [17], but it does not 
mean that it is entirely simplex. Unfortunately, even in such legal acts which should be as coherent, precise and deterministic as possible, there appear certain consistency issues and conflicts which make the rules of law defeasible.

At the beginning of our discussion on defeasible logic, legal rules and deontic rules of law, it may prove useful to focus on nonmonotonic logic.

Among the innumerable systems of nonmonotonic logic, circumscription, default logic and autoepistemic logic are the most popular and have been described in more detail. Circumscription [12] is based on first-degree classical logic (the logic of predicates), where the defeater is added directly to the formula. This may be illustrated on the following example:

$$
\begin{gathered}
\forall_{x} \operatorname{bird}(X) \wedge \neg \text { non }-\operatorname{flying}(X) \rightarrow \operatorname{flies}(X) \\
\forall_{x} \text { penguin }(X) \rightarrow \text { non }-\operatorname{flying}(X) \\
\text { bird }(\text { Tweety })
\end{gathered}
$$

Circumscription minimizes the extension of some predicates, where the extension of a predicate is the set of tuples of values the predicate is true on. This minimization is similar to the closed world assumption that what is not known to be true is false. Default logic, as proposed by Reiter [22], formalizes the reasoning with default assumptions. It introduces a new rule of inference:

$$
\frac{A: B}{C}
$$

which stipulates that if $\mathrm{A}$ is true and consistent with what is known about $\mathrm{B}$, then $\mathrm{C}$ is also true. For example:

$$
\frac{\operatorname{bird}(X): \operatorname{flies}(X)}{\operatorname{flies}(X)}
$$

This rule allows for making a speculative assumption that birds fly and in the absence of proof that a given bird does not fly, it is assumed that it does.

Autoepistemic logic developed by MacDermott [11] introduces a modal operator $M$ referred to as possible, and a modal operator L referred to as necessary. Our birds example in the autoepistemic logic can be explained as follows:

$$
\forall_{x} \operatorname{bird}(X) \wedge \neg \text { Lnon }-\operatorname{flying}(X) \rightarrow \operatorname{flies}(X)
$$

This formula implies that all birds fly unless it is known that they do not.

Generally, legal inference is non-monotonic. Therefore, the elements of the logic systems described can be found in the legal inference models which will be presented below.

Basing on background of nonmonotonic logic problems of defeasibility and defeasible reasoning were discussed by many researchers: In [20], the authors speak about inference-based defeasibility, they distinguish process-based defeasibility, referring to various inference-related features, such as the impact of time or common sense 
circumstances. Finally, we can speak of theory-based defeasibility, relating to the theories explaining the premises and bases of the argumentation process. In the case under analysis, we encounter inference-based defeasibility (defeasible rules), as well as process-bade defeasibility (the non-feasibility of paying the same tax by two different persons). A slightly different division of defeasibility is presented in another article [28] which distinguishes factual defeasibility, strong overridden defeasibility and weak overridden defeasibility. In [6] J. Hage points out that, in a fact, each rule of law is defeasible, even if no defeater is actually known. He distinguishes four types and sources of defeasibility: ontological, conceptual, epistemic and justification-related. The issue of modelling argumentation processes for defeasible logic has been dealt with, inter alia, by Sartor, Prakken, Horty, Toni and Kowalski and others.

On the grounds of default logic, Horty [9] introduced nonmonotonic deontic logic, in which the conditional command $\mathrm{O}(\mathrm{A} / \mathrm{B}) \mathrm{A}$ ought to be in case of $\mathrm{B}$ was expressed through the B:A/A rule, derived from default logic. The unconditional command $\mathrm{O}(\mathrm{A})$ was expressed as $\mathrm{O}(\mathrm{A} / \mathrm{T})$, where $\mathrm{T}$ is always true. A conflict was defined as the situation in which the conclusions from two different rules are inconsistent. In case of the conflict, he introduced the possibility to defeat one of the rules. Unfortunately, in [15] H. Prakken pointed out several disadvantages of such a solution, including but not limited to the definition of a permission and to the impossibility to represent the violation of a command.

The studies by Prakken and Sartor (including [25], [18], [17], [16]) feature a consistent model of defeasible logic, which may be practically adapted to, and internalised within, AI and law systems. In their model, the authors introduce the notion of strict $(\rightarrow)$ and defeasible implication $(\Rightarrow)$, and two types of negation, i.e. classical negation $(\neg)$ and negation as failure $(\sim)$. The model constructed comprises both implication types, and negation as failure. The authors further define various ways of defeating of the rules such as undercutting, rebutting and negating the premises. In consequence, the arguments can be coherent (when they are not challenged), acceptable (when the attacks are defeated), null and void (defeated) and defence-oriented (i.e. those which are neither justified nor defeated). Within the theory developed, the authors suggest prioritising the rules, in order to enable solving the conflicts occurring between the arguments as part of defeasible reasoning. In [25], the author further emphasises that defeasible arguments are not always applicable, which should also be considered in the model. The example described in this study gives rise to defeasibility through undercutting and rebutting. Furthermore, the authors of some studies analyse the issue of defeasibility and inference concerning the prioritisation of rules, which does not apply to our case. In [25], Sartor also draws our attention to the causes behind defeasibility, including defeasibility of the rules themselves, the dynamics of legal change, the multiplicity of legal sources, or the lack of determinism in meaning.

The Sartor and Prakkens model comprises the notion of an argument, which contains a series of defeasible and indefeasible rules. The strength of an argument is determined using the priority of the last (closest to the final conclusion) defeasible rule. The inter-argument conflict occurs when the extension of two different arguments leads to complementary conclusions. Arguments are created in an iterative 
way, justifying them at each stage, in order to avoid conflicts. Only the properly justified arguments are used at any further argumentation stages. The conflicts are solved using the priorities of individual defeasible arguments. The ultimate conclusion can be drawn only on the basis of justified arguments. This model also allows for the reinstatement of arguments, i.e. for the defeasibility of an argument which acts as a defeater for another argument.

The model of defeasible inference and conflict solving, developed by Kowalski and Toni [10], is based on a different approach, though certain elements are common. These two authors, similar to Prakken and Sartor, make a distinction into indefeasible and defeasible rules, conflict solving priorities, and two negations, i.e. ordinary negation and negation as failure. The differences arise in the definition of conflicts and in conflict solving. The predicates applied include holds $(\mathrm{r})$, defeated(r) and $\operatorname{conflict}(r$, $\left.r^{\prime}\right)$, where $\mathrm{r}$ is the underlying rule, holds(r) means that the rule is applicable (i.e. its conditions are met), defeated $(r)$ means that the rule is defeated whereas conflict $\left(r, r^{\prime}\right)$ means that there is a conflict between these two rules. In this system, the defeasible rule formulated as:

$$
A \Leftarrow B_{1}, B_{2}, \ldots, B_{n}
$$

will be satisfied in case of:

$$
\begin{gathered}
A \Leftarrow \operatorname{holds}(r) \\
\operatorname{holds}(r) \Leftarrow B_{1}, B_{2}, \ldots, B_{n}, \sim \operatorname{defeated}(r)
\end{gathered}
$$

Where:

$$
\text { defeated }(r) \Leftarrow r<r^{\prime}, \text { conflict }\left(r, r^{\prime}\right), \text { holds }\left(r^{\prime}\right)
$$

a conflict between rules $r$ and $r^{\prime}$, which the authors describe as a situation in which one of the rules has the conclusion A and the other one non-A. Such a definition of a conflict was widely criticized (e.g. in [8]) due to its limitation to the simplest conflict, based on a simplex dichotomy of A and non-A. A different standpoint on the argumentation structure is taken by T. Gordon [5]. He disapproves of the purely deductive logic-based approach to argumentation. He points out that the argumentation is highly procedural, and it is not a mechanical deduction based on the existing rules. Inferencing is dependent on the argumentation schemes referred to, inter alia, by Walton [29]. Although he obviously does not reject logic entirely, he notes that the argument creation is governed not only by pure logic. In his model, he also proposes the rules which, apart from such elements as conditions and conclusions (including negative ones), may also include certain exceptions (i.e. the conditions which defeat the rule provided they are true) and assumptions. In case of the conflict, which is defined traditionally (as a situation in which one of the rules has the conclusion A and the other one non-A), the author proposes assigning priorities to the rules, which should be inferred from other rules. Under certain circumstances, these rules may be considered invalid or excluded from the inference. The system also allows for representing the interpretation rules, the inference rules, the rules of priority assignment (e.g. based on the principle of lex posteriori), or the rules defeating other rules.

J. Hage in [7] takes a more comprehensive view on the issue of rules, legal expertise representation and legal inference. His reason-based logic goes beyond the scope of the classical logic of predicates. He introduces, inter alia, the distinction into classical 
rules and the impact of one specific state of affairs on the other. Such an impact may be either decisive or contributive. Only the classical negation (and not the negation as failure) may be applied to the rules discussed. Under certain circumstances, one rule may also be considered invalid, or excluded. On the other hand, it may be deemed applicable even if certain conditions are not satisfied (for example, the author indicates the possibility to use the analogy).

A crucial aspect of this study is to model the conflict between the rules of law, which may be (and often is) treated as a clash between two distinct arguments (or their subsets), leading to two mutually exclusive conclusions, i.e. one rule rebuts the other one [25]. In [18], the rules are deemed conflicting when one of them attacks the other one, i.e. when the conclusion of one rule is complementary to the conclusion or condition of the other one. In [5], [13], the rules are conflicting when one has a conclusion $\mathrm{P}$, and the other one not $\mathrm{P}$. Nute in [13] points out that the conflicts arise not only when the rule conclusions represent pairs $\mathrm{P}$ and non-P, but also in the case of other rules with incompatible conclusions. A thought-provoking approach to the deontic rules conflict is presented in [28], where two command rules are considered conflicting when the conditions of both rules are true, whereas their conclusions are contradictory.

The conflict model proposed by J. Hage is relatively complex, and it is based on the assumption that the conflict occurs only when a conclusion from one rule implies $\mathrm{A}$, and from the other one non-A, though it may result from the commonsense-based limitations, related to the circumstances analysed. Such a model is suitable for the case analysed in this study, where the conflict occurs not so much between specific legal rules, but rather between these rules and the commonsense-based and legal limitations. The solution to the conflict under the RBL model is based on a previously defined prevalence of one rule over the other (i.e. it is similar to other priority-based solutions) and on the use of an inference rule, which does not allow for the weaker rule to apply.

As a result, the model proposed in [7] is very good description of the conflict between the rules analysed.

There are many ways to solve the conflicts between various rules, most of which are based on the rules-specific attributes, such as the date of enactment or the level of detail. They are usually modelled by prioritising some of the rules and putting them in a certain order, e.g., according to the assessment level of one of the attributes (e.g., the level of detail) [17], [13], [18]. As in the case of [17] and other works, this study employs the criterion of specificity (the lex specialis principle), combined with prioritising certain conflicting rules. Although the level of detail comparison was, formally speaking, defined in [13], most studies (including this one) provide no such definition, as they assume that this notion stems from the common sense knowledge and, as such, is declared by the author of the model.

Despite a number of more or less complex theories regarding the legal inference models, so far not many complete advisory systems have been developed, which would map the rules of law. The advisory system regarding the British Nationality Act [26], and more specifically the conferral of the British citizenship, is currently the most famous one. It was written in the PROLOG language. Its authors emphasise that, 
considering the precise and deterministic character of this legal act, its implementation was possible without any serious interference with the language logic. The system is based on deduction, and it only uses negation as failure. Predicative negations were created as separate predicates. Naturally, to implement such a solution it was necessary to solve a series of problems related to knowledge representation, as was quite specifically discussed in [26]. Nevertheless, it is worth noting that, in the reference system, one knowledge base combines legal rules with the commonsense knowledge, forcing one specific interpretation of the former. Although such a mechanism may prove efficient in certain situations (for very unambiguous and deterministic acts of law), it generally triggers a significant limitation of the programme functions to one predefined interpretation. Prolog was also used in a system implementing canadian income tax law [27]. In [3] authors described their attempts to implement italian tax law in rule based expert system.

The Carneades system of argumentation modelling, proposed by T. Gordon, is another solution based on knowledge and legal inference modelling. Conceptually speaking, this tool differs from the all described earlier ones. It does not serve as an automatic extraction of legal opinions, but rather as an instrument to model the legal discourse between two parties. It makes use of the mechanisms described earlier in this study.

\section{The Act}

The analysis covers Article 3 of the Agricultural Tax Act [1]:

Art. 3.

1. Natural persons, legal persons, and corporate units (including those without legal personality) are considered agricultural tax payers as long as they are:

1) owners of land, subject to Paragraph 2,

2) owner-like possessors of land,

3) perpetual users of land,

4) possessors of land constituting the ownership of the State Treasury, or of any local government unit, where any such possession:

a. arises from the contract concluded either with the respective owner or with the Agricultural Property Agency of the State Treasury, or from any other legal title, or

b. is not subject to any legal title, except for any land forming part of the Agricultural Property Resources of the State Treasury, or managed by the State Forests, in which case the organisational unit of the Agricultural Property Agency of the State Treasury or of the State Forests, respectively, functions as the respective owner.

2. Where land is subject to owner-like possession, the tax obligation is upon the owner-like possessor. 
3. Where land of an agricultural farm was leased, whether in whole or in part, under a lease contract concluded in compliance with the provisions on the social security of farmers, the lessee acts as the agricultural tax payer.

4. Where land of an agricultural farm was contributed to a production cooperative in the form of in-kind contribution, the manufacturing cooperative acts as the agricultural tax payer.

5. Where the land referred in Article 1 constitutes a common property of two or more entities, they form a separate object covered by the agricultural tax, and the corresponding tax obligation is on each and every co-owner (possessor), subject to Paragraph 6.

6. Where the land referred to in Paragraph 5 constitutes an agricultural farm, the tax obligation is on this co-owner (possessor) who entirely runs this agricultural farm.

To analyse the reference act of law, it is necessary to pay attention to other related provisions. Act 115, Item 74 stipulates that land leased for perpetual usufruct may only be owned by the State Treasury whereas Article 3a of the reference act implies that the tax obligation, referred to in Article 3, applies neither to the State Treasury nor to the commune (in Polish: gmina).

\section{Model of the Act}

A model of the legal act under analysis is presented below. It hinges upon the conviction that it should accurately mirror the rules content, including their drawbacks, such as inconsistency or possible conflicts. The act was modelled using basic logical correlations and assumptions, as presented in the studies by Sartor and Prakken [25], [19], [21], [17] (and more). The model employs both classical and defeasible implication, as well as weak negation (negation as failure).

The possibility to use two negations and the priority-based conflict solving mechanism was the principal reason behind the choice of the Sartor and Prakkens logic to represent the act of law at issue. To some extent, the model in question was simplified, as the priorities defeasibility was abandoned. Given that the conflict identification mechanism in the Sartor and Prakkens model is not fully adequate to the conflicts which occur in the act of law analysed (some conclusions are mutually exclusive, considering the commonsense-based limitations but they do not have to be complementary), the use was made of a partly simplified conflict model from [7]. Nevertheless, the (priority-based) conflict solving mechanism itself comes from the Sartor and Prakkens model.

Such an approach to rules representation (with all possible imperfections of the legal act being left in the model) and translating such interpretation into an inference mechanism seems more accurate as it is closer to the line of reasoning employed by lawyers. Using the approach presented in [7], the model was supplemented with both 
common sense constraints and the constraints resulting from other provisions of law.

1.1) owner $(X, G) \wedge($ natural_person $(X) \vee$ legal_person $(X) \vee$

corporate_units_inclureding_those_without_legal_personality $(X)) \wedge$

$\sim$ owner - like possesor $(, G) \wedge \operatorname{land}(G) \Rightarrow \operatorname{tax} \operatorname{payer}(X, G)$.

1.2) (natural_person $(X) \vee$ legal_person $(X) \vee$

corporate_units_including_those_without_legal_personality $(X)) \wedge$

owner - like possesor $(X, G) \wedge$ land $(G) \Rightarrow$ tax_payer $(X, G)$.

1.3) (natural_person $(X) \vee$ legal_person $(X) \vee$

corporate_units_including_those_without_legal_personality $(X)) \wedge$

perpetual_user_of_the_land $(X, G) \Rightarrow \operatorname{tax} \operatorname{payer}(X, G)$.

1.4) a. (natural_person $(X) \vee$ legal_person $(X) \vee$

corporate_units_including_those_without_legal_personality $(X)) \wedge$

$\operatorname{possessor}(X, G) \wedge$ owner $(Y, G) \wedge($ state_tresaury $(Y) \vee l o c a l$ goverment_unit $(Y)) \wedge$

$($ agricultural_property_agency $(Y) \vee$ state_forest $(Y)) \wedge(\operatorname{contract}(X, Y) \vee$

other_legal_title $(X, Y)) \wedge$

$\operatorname{land}(G) \Rightarrow \operatorname{tax} \operatorname{payer}(X, G)$.

1.4) b. (natural_person $(X) \vee$ legal_person $(X) \vee$

corporate_units_including_those_without_legal_personality $(X)) \wedge$ possessor $(X, G) \wedge$ owner $(Y, G) \wedge($ state_tresaury $(Y) \vee$ local_goverment_unit $(Y)) \wedge$

$\sim$ agricultural_property_agency $(Y) \wedge$

$\sim \operatorname{state\_ forest}(Y) \wedge \operatorname{land}(G) \Rightarrow$ tax payer $(X, G)$.

2. (natural_person $(X) \vee$ legal_person $(X) \vee$

corporate_units_including_those_without_legal_personality $(X)) \wedge$

owner - like_possesor $(X, G) \wedge \operatorname{land}(G) \Rightarrow \operatorname{tax}$ _payer $(X, G)$.

3. (natural_person $(X) \vee$ legal_person $(X) \vee$

corporate_units_including_those_without_legal_personality $(X)) \wedge$ leased $(G) \wedge$

lessee $(X, G) \wedge$ under_lease_contract $(G, X) \wedge$ land $(G) \Rightarrow \operatorname{tax} \_$payer $(X, G)$.

4. manufacturing_cooperative $(X) \wedge$ contribution $(G, X) \wedge \operatorname{land}(G) \Rightarrow$

tax_payer $(X, G))$.

5. ((natural_person $(X) \vee$ legal_person $(X) \vee$

corporate_units_including_those_without_legal_personality $(X)) \wedge$ co-owner $(X, G) \wedge$

$\operatorname{land}(G) \wedge \sim($ agricultural_farm $(Y) \wedge$ part_of_agricultural_farm $(G, Y) \wedge$

entirely_runs_the_agricultural_farm $(X, Y)) \Rightarrow \operatorname{tax} \operatorname{payer}(X, G)) \vee$

$(($ natural_person $(X) \vee$ legal_person $(X) \vee$

corporate_units_including_those_without_legal_personality $(X)) \wedge$ co-possessor $(X, G) \wedge$

$\operatorname{land}(G) \wedge \sim($ agricultural_farm $(Y) \wedge$ part_of_agricultural_farm $(G, Y) \wedge$

entirely_runs_the_agricultural_farm $(X, Y)) \Rightarrow \operatorname{tax} \operatorname{payer}(X, G))$. 
6. ((natural_person $(X) \vee$ legal_person $(X) \vee$

corporate_units_including_those_without_legal_personality $(X)) \wedge$ co-owner $(X, G) \wedge$ agricultural_farm $(Y) \wedge$

part_of_agricultural_farm $(G, Y) \wedge$ entirely_runs_the_agricultural_farm $(X, Y) \wedge$

$\operatorname{land}(G) \Rightarrow$ tax_payer $(X, G)) \vee(($ natural_person $(X) \vee$ legal_person $(X) \vee$

corporate_units_including_those_without_legal_personality $(X)) \wedge$ co-possessor $(X, G) \wedge$

agricultural_farm $(Y) \wedge$ part_of_agricultural_farm $(G, Y) \wedge$

entirely_runs_the_agricultural_farm $(X, Y) \wedge \operatorname{land}(G) \Rightarrow \operatorname{tax} p$ payer $(X, G))$.

Constraint taken from art $3 \mathrm{a}[1]$ :

1. state_treasury $(X) \wedge \operatorname{owner}(X, G) \Rightarrow \neg \operatorname{tax} \operatorname{payer}(X, G)$

Constraint from act 115 pos. 741[1]:

2. perpetual_user_of_the_land $(X, G) \wedge \operatorname{owner}(Y, G) \Rightarrow \operatorname{state}$ _treasury $(Y)$

Commonsense constraints:

If a given plot of land has both the owner and the perpetual user who has leased it to a third party, only one of them can act as a taxpayer. If a given plot of land has the owner who has leased it to a third party, only one of them can act as a taxpayer.

3. owner $(X, G) \wedge$ perpetual_user $(Y, G) \wedge$ leese $(Z, G) \Rightarrow((\operatorname{tax}$ payer $(X, G) \wedge \neg \operatorname{tax}$ payer $(Y, G) \wedge$ $\neg$ tax_payer $(Z, G)) \vee\left(\neg \operatorname{tax} \_\right.$payer $\left.(X, G) \wedge \operatorname{tax} \operatorname{payer}(Y, G) \wedge \neg \operatorname{tax} \operatorname{payer}(Z, G)\right) \vee$ $(\neg \operatorname{tax} \operatorname{payer}(X, G) \wedge \neg$ tax payer $(Y, G) \wedge \operatorname{tax} \operatorname{payer}(Z, G)))$

4. owner $(X, G) \wedge$ leese $(Y, G) \Rightarrow\left(\left(\operatorname{tax} \_\right.\right.$payer $\left.(X, G) \wedge \neg \operatorname{tax} \operatorname{payer}(Y, G)\right) \vee(\neg \operatorname{tax} \operatorname{payer}(X, G) \wedge$ tax_payer $(Y, G)))$

The construction of the model presented was intended to accurately reflect the content of the legal act, together with any potential imperfections, including ambiguities or loopholes. For example paragraph and rule 1.1 include owner-like_possesor but paragraph and rule 1.2) does not include $\sim$ owner.

\section{Imperfection of the model}

The model created was assumed to precisely represent the wording of the legal act, and as such should contain any provision-specific imperfections, including imprecision, undefined assumptions, loopholes, ambiguity, and the like. When compared to other legal acts, the Agricultural Tax Act shows positive features, in terms of precision and 
completeness. However, even the most deterministic legal acts include many of the imperfections mentioned. When implementing the model of Article 3 of the Act at issue, the most important problem relates to the potential conflict of rules of law, connected with integrity constraints (which stem from common-sense knowledge) of the conclusions which stem from these rules.

For instance, the rule in Point 1.1) stipulates that a land owner is the agricultural tax payer (on condition that where the land belongs to an owner-like possessor, the latter acts as the agricultural tax payer). On the other hand, Point 3 specifies that where the land is leased under a contract concluded in compliance with the provisions on the social security of farmers, then the lessee acts as the agricultural tax payer. Assuming that the land has an owner who has leased the said land under a contract concluded in the mode specified above, then both the owner and the lessee act as agricultural tax payers, which violates the integrity constraint specifying that one and the same tax may not be paid by two different persons. A similar situation occurs where the owner has contributed the land to a given production cooperative. In this event, the owner acts as a tax payer in accordance with Point 1.1), and so does the production cooperative in accordance with Point 4 . This results in a conflict of the provisions in Point 1.1) and the latter part of the provision in Point 5 concerning the joint possession, as well as between rule 1.1) and the latter part of rule 6 . The above conflicts arise from the integrity constraints violation. In the cases, the said constraint precludes the possibility of there being two simultaneous payers of one and the same tax.

\section{Interpretation}

The conflicts mentioned are obviously nothing odd in the law. Actually, similar conflicts are found in most acts, and there is an array of commonly known solutions. Considering the Act under analysis, one may apply the lex specialis derogat legi generali principle, under which the specific act (provision) derogates from (prevails over) the general regulation. Therefore, in the event where there are both the owner and the lessee, who has leased the land from the owner under a contract concluded in compliance with the provisions on the social security of farmers, it is the lessee who acts as a tax payer. A similar principle should apply to the remaining conflicts. This results from the fact that the rules at issue constitute an exception (though not expressly specified) to a more general provisions. The case of interaction between rules 1.1) and 1.3) seems similar. However, the integrity constraints in this event do not result in any conflict, given that the perpetual usufruct may only concern the land owned by the State Treasury which cannot act as an agricultural tax payer, as stipulated in separate provisions (what is described by the constraints of the model).

The conflict between the rules of the act at issue is accurately described on the model in [7] (Chapter 5 concerning the rule coherence). Comparing his model to other models presented in [5], [13], and [28], the author points out, inter alia, that the source of conflicts may not only stem from the complementary nature of the conclusions ( $\mathrm{P}$ 
and non-P, referred to as the logical conflict), but also from incompatibility of the factual states they describe. The compatibility (or incompatibility) of the factual states may be evaluated through additional constraints (the rules may be incompatible with respect to a certain constraints). Such a model may properly represent a specific conflict type, applicable to the act of law in question.

Basing on[7] (and simplifying it) we may say that two rules are in conflict while they have true conditions and if their conclusions may not be simultaneously true, given the integrity constraints.

\section{The model comprising lex specialis derogat legi generali}

The provisions specificity assessment and comparison constitutes the essence of the lex specialis derogat legi generali rule-based inference. The comparison may be based on various aspects, depending on the nature of a given problem and common-sense knowledge. In the cases analysed, the provisions specificity comparison is based on the analysis of the conditional aspect of these rules, where the more specific rule has more restricted conditions.

A number of articles devoted to legal inference modelling suggest introducing a system of conflicting rules or priorities which would order the conflicting rules. As a result, in the event of conflict, the weaker rule would be defeasible. The ordering may be based on various factors, such as time (lex posteriori), the hierarchy of rules, or the level of detail (lex specialis). Obviously, the attribution of priorities and order stem from the common sense knowledge and, as such, they are usually directly declared by the system creator, though some studies seem to opt for the inference mechanisms regarding priorities (e.g., [18], [19] and other). The model described in this study, similar to other models presented in the articles mentioned, is based on ordering the rules according to the level of detail, with the order being directly declared by the author. The conflict solving mode used in the study is close to the models presented in various studies by Sartor, Prakken, and other authors (e.g., [24], or [18] but without priorities defeasibility). The notion of assessing the level of detail for legal rules was defined, inter alia, in [24].

The development of an inference model based on lex specialis derogat legi generali starts with verifying whether a given pair of rules stand in contradiction. This may be done by using the model presented in [7].

This should be followed by comparing the specificity of the pairs of conflicting rules under analysis. A given set of conflicting rules $\mathrm{K}$ may be ordered using the generality criterion. In this way, we obtain an ordered set $(\mathrm{K},>)$, under which for two rules, $\mathrm{r}_{m}$ and $\mathrm{r}_{n}$, where $\mathrm{r}_{m} \in \mathrm{K}$ and $\mathrm{r}_{n} \in \mathrm{K}$, the statement: $\mathrm{r}_{m}>\mathrm{r}_{n}$ means that $\mathrm{r}_{m}$ is more specific than $\mathrm{r}_{n}$.

The most straightforward solution allowing for the implementation of the lex specialis derogat legi generali principle would be to attribute beforehand certain priorities to particular rules from each set of conflicting rules, following the specificity assessment. Although such a solution is a considerable simplification of the reality, it still allows 
for quite an efficient dealing with the problem of conflicting rules. It also properly represents the way of reasoning for this particular act.

There are five sets of conflicting rules in the example analysed, namely:

$\mathrm{K} 1$ comprising Rule 1.1) and Rule 3, which may be presented as $\mathrm{K} 1=\mathrm{r}_{1.1}$ ), $\mathrm{r}_{3}$

K2 comprising Rule 1.1) and Rule 4, which may be presented as $\mathrm{K} 2=\mathrm{r}_{1.1}$ ), $\mathrm{r}_{4}$

K3 comprising Rule 1.1) and Rule 5, which may be presented as $\mathrm{K} 2=\mathrm{r}_{1.1}$ ), $\mathrm{r}_{5}$

K4 comprising Rule 1.1) and Rule 6, which may be presented as $K 2=r_{1.1}$ ),$r_{6}$

In each pair, one may distinguish a less and a more specific rule:

$\mathrm{K} 1: \mathrm{r}_{3}>\mathrm{r}_{1.1}$

$\mathrm{K} 2: \mathrm{r}_{4}>\mathrm{r}_{1.1}$

K3: $r_{5}>r_{1.1}$

$\mathrm{K} 4: \mathrm{r}_{6}>\mathrm{r}_{1.1}$

The lex specialis derogat legi generali principle specifies that whenever there is a conflict, the more specific rule voids the less specific one. Therefore, for a given set of conflicting rules $\mathrm{K}$, the most specific rule is enforced, while the remaining ones are made unenforceable. In the analysed case, rule $r_{3}$ voids rule $r_{1.1}$ for $K 1$, rule $r_{4}$ voids rule $\mathrm{r}_{1.1)}$ for $\mathrm{K} 2$, etc.

The cases analysed reveal one more specific feature, namely that rule $r_{1.1)}$ appears in four groups, which does not necessarily mean that both groups have something in common. The specificity assessment criterion may differ for each of them, and rules $\mathrm{r}_{3}$ and $\mathrm{r}_{4}$ do not have to stand in contradiction (and they do not in the case analysed). The possibility of such a situation to arise may impose the need to attribute as many priorities (determining the specificity) to each rule as there are conflicting sets to which it belongs.

\section{Implementation}

The author decided to use the DROOLS engine due to an extended range of parameter setting options and complete integration with the JAVA language, which offers wide possibilities to expand the system. As the DROOLS engine makes use of production rules and RETE algorithm, also allows for freely implementing the provisions of law, as shown on the example below.

Generally speaking, various types of knowledge are represented in the system in different ways. The common sense knowledge is partly represented as ontology, comprising also the common sense integrity constraints (banned values, inter-conceptual relations, attribute value limitations, banned instances, etc.). It currently comprises 94 concepts (39 of which are used in the system section implementing Article 3 of the legal act) which make it possible to thoroughly describe the cases regulated by the act of law analysed. The conflict solving part of common sense knowledge is recorded as attributes, whereas the provisions of the act of law are expressed as rules.

The method used to both implement selected rules and to solve the conflict between them is illustrated on the example of two conflicting rules, presented below: 


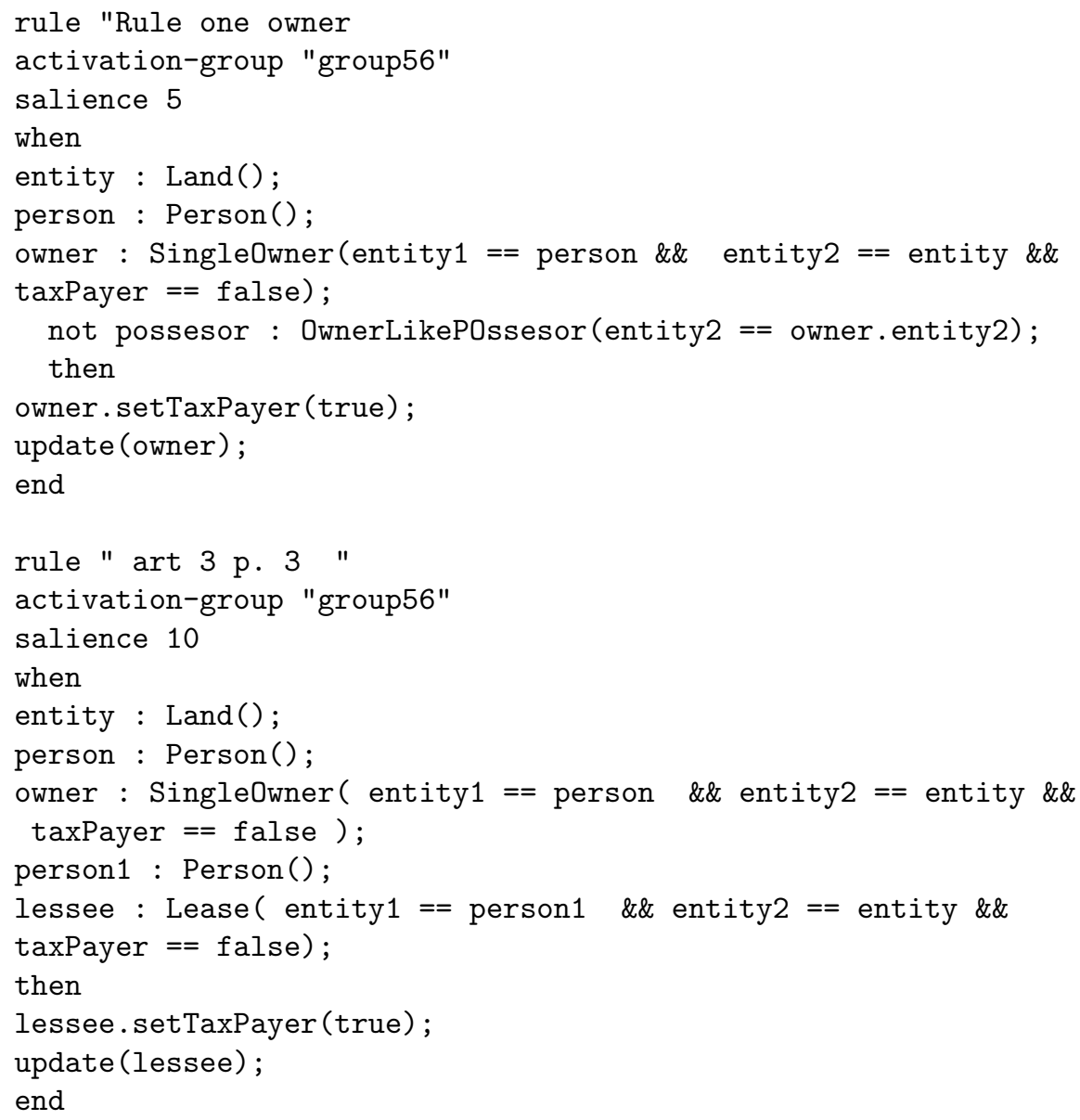

It is worth to take a look at the rules above the first one maps point 1.1) of the model act (i.e. when there is one land owner), while the second one point 3.3) (i.e. when there is also a lessee). The DROOLS system makes it possible to give various attributes to the rules, the use of which allowed for implementing the conflict solving mechanism. Both rules analysed belong to one group of conflicting rules (We use the activation-group attribute, which allows for only one rule in the group to be "fired"). The salience attribute defines the priority. The second rule exhibits a higher value of this attribute, as a result of which only this rule will be activated in the event of conflict.

As regards the conditional aspect of both rules, the identifiers are assigned to the relevant ontology classes, and the conditions which must be satisfied are specified. On the right-hand part the "true" values are assigned to the "taxpayer" element, and the working memory update is performed.

At first, it was assumed that the rules record in the system must be as close to the provision content as possible, even at the cost of inconsistency and conflicts be- 
tween rules. The example of two conflicting rules shows that, on the one hand, the implementation corresponds to the model of the conditional and conclusive elements of the rule but, on the other hand, the system is still unable to identify the conflicting rules and to attribute them to the relevant priorities. As a result, it is indispensable to consider the conflicting aspect of the rules and their priorities within the attributes.

\section{Conclusions}

Advisory legal systems are still too imperfect to be commonly put into practice. The simulation of inference processes performed by lawyers can be seen as one way to create such a tool. In order to simulate such a process as accurately as possible, it is indispensable to make a clear-cut distinction between the provision itself, and its interpretation and inference mechanisms. This distinction would allow for preserving both the universal character of the provision and its applicability to various legal problems. Unfortunately, this very often proves difficult to achieve, though the level of difficulty varies between legal acts. Tax rules, given their specificity, require linguistic interpretation, thereby making the system development slightly less complicated, though still not easy. The author of this study attempted at representing the content of a legal act in the knowledge base as precisely as possible, including any loopholes and inconsequence it exhibits, thereby transferring the problem of dealing with them into the inference process. The advisory system operating in the scope of the Agricultural Tax Act served as the means for presenting the model and implementation of one way of dealing with conflicting provisions. Undoubtedly, the model and implementation described are far from ideal and allow for solving only part of the problems related to conflicts of laws. The model analysed does not cover any other ways of dealing with conflicts, as they have no application to the case under consideration. Although the knowledge base is far closer to the direct model of the Act than it was in the previous version of the system [30]. However, it is worth mentioning that the mechanism described cannot be used to solve other serious problems. It cannot automatically verify which provision in each group is the more specific, which would be extremely useful in solving the problems of collision between legal regulations.

\section{References}

[1] Agricultural tax act. http://prawo-nieruchomosci.krn.pl/Ustawa-o-podatkurolnym-1_2_36.html (2010)

[2] Bench-Capon, T., Sartor, G.: Theory based explanation of case law domains:. In: ICAIL '01: Proceedings of the 4th international conference on Artificial intelligence and law, pp. 12-21. ACM, New York, NY, USA (2001) 
[3] Borsari, G., Cevenini, C., Contissa, G., Morini, S., Sartor, G., Still, P.: Hare: an italian application of softlaw's statute expert technology. In: ICAIL '05: Proceedings of the 10th international conference on Artificial Intelligence and Law, pp. 225-229. ACM, New York, NY, USA (2005)

[4] Gordon, T.: Some problems with prolog as a knowledge representation language for legal expert system. International Review of Law, Computers and Technology 3, 52-67 (1987)

[5] Gordon, T.: Constructing arguments with a computational model of an argumentation scheme for legal rules: Interpreting legal rules as reasoning policies. In: Proceedings of the 11th International Conference on Artificial Intelligence and Law, pp. 117-121. ACM, New York, NY, USA (2007)

[6] Hage, J.: Law and defeasibility. Artificial Intelligence and Law 11, 221-243 (2003)

[7] Hage, J.: Studies in Legal Logic. Springer (2005)

[8] Horty, J.: Argument construction and reinstatement in logics for defeasible reasoning. Artificial Intelligence and Law 9, 1-28 (2001)

[9] Horty, J.F.: Nonmonotonic techniques in the formalisation of commonsense normative reasoning. Proceedings Workshop on Nonmonotonic Reasoning pp. 74-84 (1993)

[10] Kowalski, R., Toni, F.: Abstract argumentation. Articial Intelligence and Law 4, 275-296 (1996)

[11] MacDermott, D.: Non-monotonic ii- non-monotonic modal theories. Journal of ACM 29(1), 33-57 (1982)

[12] Mccarthy: Circumscription a form of non-monotonic reasoning. Artificial Intelligence 13, 27-39 (1980)

[13] Nute, D.: Defeasible logic. In: INAP'01: Proceedings of the Applications of prolog 14th international conference on Web knowledge management and decision support, pp. 151-169. Springer-Verlag, Berlin, Heidelberg (2003)

[14] Oskamp, A.: Model for knowledge and legal expert systems. Artificial Intelligence and Law 1, 245-274 (1992)

[15] Prakken, H.: Two approaches to the formalisation of defeasible deontic reasoning. Studia Logica pp. 73-90 (1996)

[16] Prakken, H.: Coherence and flexibility in dialogue games for argumentation. Journal of logic and computation 15, 1009-1040 (2005)

[17] Prakken, H.: Formalising ordinary legal disputes: a case study. Artificial Intelligence and Law 16, 333-359 (2008) 
[18] Prakken, H., Sartor, G.: A system for defeasible argumentation, with defeasible priorities, Lecture Notes in Computer Science, vol. 1085, pp. 510-524. Springer Berlin / Heidelberg (1996)

[19] Prakken, H., Sartor, G.: Argument-based extended logic programming with defeasible priorities. Journal of Applied Non-classical Logics 7(1) (1997)

[20] Prakken, H., Sartor, G.: The three faces of defeasibility in the law. Ratio Juris 17(1), 118-139 (2004)

[21] Prakken, H., Sartor, G.: Formalising arguments about the burden of persuasion. In: ICAIL '07: Proceedings of the 11th international conference on Artificial intelligence and law, pp. 97-106. ACM, New York, NY, USA (2007)

[22] Reiter, R.: A logic for default reasoning. Artificial Intelligence 13, 81-132 (1980)

[23] Sartor, G.: The structure of norm conditions and nonmonotonic reasoning in law. In: ICAIL '91: Proceedings of the 3rd International Conference on Artificial intelligence and law, pp. 155-164 (1991)

[24] Sartor, G.: Normative conflicts in legal reasoning. Artificial Intelligence and Law 1, 209-235 (1992)

[25] Sartor, G.: A simple computational model for nonmonotonic and adversarial legal reasoning. In: ICAIL '93: Proceedings of the 4th international conference on Artificial intelligence and law, pp. 192-201 (1993)

[26] Sergot M, J., Sadri, F., Kowalski R, A., Kriwaczek, F., Hammond, P., Cory H, T.: The british nationality act as a logic program. Communications of the ACM 29(5), 370-386 (1986). DOI http://doi.acm.org/10.1145/5689.5920

[27] Sherman, D.: A prolog model of the income tax act of canada. In: ICAIL '87: Proceedings of the 1st international conference on Artificial intelligence and law, pp. 127-136 (1987)

[28] Van Der Torre L W, N., Yao-Huata, N.: Defeasible Deontic Logic, chap. The Many Faces Of Defeasibility In Defeasible Deontic Logic, pp. 79-122. Kluwer (1997)

[29] Walton, D.: Fundamentals of Critical Argumentation. Cambridge University Press (2006)

[30] Zurek, T., Kruk, E.: Supporting of legal reasoning for cases which are not strictly regulated by law. In: ICAIL '09: Proceedings of the 12th International Conference on Artificial Intelligence and Law, pp. 220-221 (2009) 